\title{
Derrame pleural refractario en el lupus eritematoso sistémico del niño. Reporte de caso
}

\author{
Rogelio Sancho-Hernández, $\bowtie$ Gabriel Gutiérrez-Morales, Francisco Javier Cuevas-Schacht
}

Instituto Nacional de Pediatría, Ciudad de México, Distrito Federal.

Trabajo recibido: 30-VI-2014; aceptado: 08-X-2014

\begin{abstract}
RESUMEN. Presentamos el caso clínico de un adolescente de 14 años de edad con derrame pleural masivo y bilateral en el curso de un lupus eritematoso sistémico y refractario al tratamiento esteroideo e inmunosupresor. Se describe la revisión de la literatura en la edad pediátrica y el análisis de las opciones terapéuticas actuales.
\end{abstract}

Palabras clave: Derrame pleural refractario, lupus eritematoso sistémico, opciones terapéuticas.

ABSTRACT. We report the case of a 14 year old with massive bilateral pleural effusion in the course of systemic lupus erythematosus refractory to steroid and immunosuppressive therapy; the review of literature in children is described and current therapeutic options are discussed.

Key words: Refractory pleural effusion, systemic lupus erythematosus, treatment options.

\section{INTRODUCCIÓN}

La pleuritis es la manifestación pleuropulmonar más común del lupus eritematoso sistémico, está asociada entre un 30 a $50 \%$ a derrame pleural unilateral o bilateral. ${ }^{1-3}$ Se manifiesta de manera aislada o asociada a la actividad inmunitaria de la enfermedad sistémica. ${ }^{3}$ El líquido pleural es un exudado con presencia de anticuerpos antinucleares (ANA); y los derrames pleurales masivos con disnea y refractarios al tratamiento convencional son infrecuentes en la edad pediátrica y no han sido reportados.

\section{MATERIAL Y MÉTODOS}

Se describe la presentación clínica de un adolescente con derrame pleural masivo bilateral y refractario al manejo esteroideo e inmunosupresor. Se hizo una revisión de la literatura en inglés y español en Medline y PubMed durante los últimos 30 años con los términos «lupus y derrame pleural refractario» (sin respuesta a la terapia con esteroides sistémicos) en niños y adultos. Se analizaron las opciones de tratamiento conservador y quirúrgico para la toma de decisiones en la población pediátrica.

\section{PRESENTACIÓN DE CASO}

Masculino de 14 años de edad sin antecedentes heredofamiliares ni perinatales de importancia, contacto con familiar tosedor crónico; refirió cefalea, fiebre de alto grado acompañada de diaforesis. A su ingreso presentó artralgias, flogosis y disnea con dolor pleurítico izquierdo. La somatometría fue normal para la edad, con síndrome de derrame pleuropulmonar en hemitórax izquierdo, hepatomegalia y adenopatía axilar. La radiografía torácica confirmó derrame pleural izquierdo.

Los paraclínicos mostraron anemia con hemoglobina de 7.7 , leucocitos de 6,200 con neutrófilos de $72 \%$, monocitos de $8.7 \%$ y plaquetas de 251 mil; velocidad de sedimentación globular de $52 \mathrm{~mm} / \mathrm{h}$, serología para VIH y baciloscopias negativas, proteinuria y hematuria. El líquido pleural expuso un exudado con proteínas de 4,000 , glucosa de $99 \mathrm{mg} / \mathrm{dL}$ y celularidad escasa con cultivos negativos, la adenosina desaminasa en $32 \mathrm{U} / \mathrm{L}$, la biopsia del conglomerado ganglionar axilar mostró hiperplasia linfoide y los anticuerpos antiDNA y ANAS positivos. De la expectoración inducida se reportó prueba de PCR para M. tuberculosis de 0.715 (positivo), iniciando tratamiento antifímico. Evolucionó con síndrome nefrítico, se reunieron los criterios diagnósticos para lupus eritematoso sistémico (anemia hemolítica, 
derrame pleural, glomerulonefritis y anticuerpos positivos). Se agregó bloqueo incompleto de rama derecha en el electrocardiograma y la ecocardiografía mostró pequeño derrame pericárdico con presión de la arteria pulmonar de $30 \mathrm{mmHg}$ y fracción de eyección sistólica del $59 \%$. La frotis de sangre periférica fue normal. Se incrementó la disnea y dificultad respiratoria a pesar del tratamiento antifímico e inmunosupresor, radiológicamente fue corroborado derrame pleural bilateral, cursando con bradicardia sintomática que requirió de la colocación de marcapasos e inicio de anticoagulación por trombosis de la vena ilíaca izquierda. Después de dos toracocentesis evacuadoras que remitían temporalmente disnea, se decidió insertar un catéter percutáneo vía intercostal en cada hemitórax y obtener durante 28 días un total de $48 \mathrm{~L}$ de líquido pleural, se evitó la inserción de una sonda pleural por el riesgo probable de pleuresía tuberculosa y la posibilidad de una fístula pleurocutánea agregada (figura 1).

La actividad lúpica fue tratada prontamente con metilprednisolona en altas dosis, gama globulina intravenosa y rituximab sin mejoría alguna; fueron corregidos estados trasudativos de hipoalbuminemia, sobrecarga hídrica e hiponatremia. Bajo este panorama es considerado derrame pleural masivo, bilateral y refractario a manejo conservador, se realiza tratamiento quirúrgico con drenaje pleural y adherensiolisis del pulmón izquierdo atrapado con toma de biopsia pleural y pleurectomía parcial con pleurodesis química con yodo povidona al 1\% por toracoscopia videoasistida. Del hemitórax derecho, una vez descartado por toracoscopia la presencia de un pulmón atrapado y confirmando la expansión pulmonar, se decidió instilar bajo visión pleurodesis química con yodo povidona al $1 \%$ y pinzamiento por cuatro horas de la sonda pleural (figuras 2 y 3 ). Se instiló vía intrapleural por tubo de toracostomía derecha y una sesión más con yodo povidona sin complicaciones. Con evolución satisfactoria fueron retirados los drenajes pleurales al tercer y cuarto día y documentadas la expansión pulmonar clínica y radiológica; y sin recurrencias a dos años de vigilancia y tratamiento médico inmunosupresor. El reporte histopatológico documentó pleuritis aguda y crónica inespecífica mayormente acentuado alrededor de los vasos sanguíneos, con hiperplasia mesotelial e infiltrado linfoplasmocitario. La citología del líquido pleural mostró células mesoteliales reactivas mezcladas con linfocitos.

\section{DISCUSIÓN}

El derrame pleural y la pleuritis representan un $61 \%$ de los hallazgos patológicos en órganos afectados por lupus eritematoso sistémico con inicio temprano en la infancia. Sólo son superados por la neumonitis intersticial crónica y la hemorragia alveolar (73\%), se ha llegado a integrarlos en un síndrome pleuropulmonar lúpico. ${ }^{4-6}$ Han sido reportados cambios fibróticos con debilidad muscular diafragmática que condicionan un patrón pulmonar restrictivo denominado síndrome de pulmón encogido. ${ }^{7-9} \mathrm{El}$ dolor pleurítico se presenta en $45-60 \%$ con o sin derrame pleural. ${ }^{1,2}$

El derrame pleural es un criterio de inclusión diagnóstico para lupus eritematoso sistémico y comúnmente representa las complicaciones cardiopulmonares secundarias más que una pleuritis lúpica primaria de la enfermedad sistémica. La pleuritis lúpica es la primera manifestación de la enfermedad en sólo el 10\%; pero es un dato clínico temprano en el $30 \%$ de la enfermedad sistémica con inicio temprano en la infancia, casi siempre precedida de artralgias y pericarditis. ${ }^{10-13}$
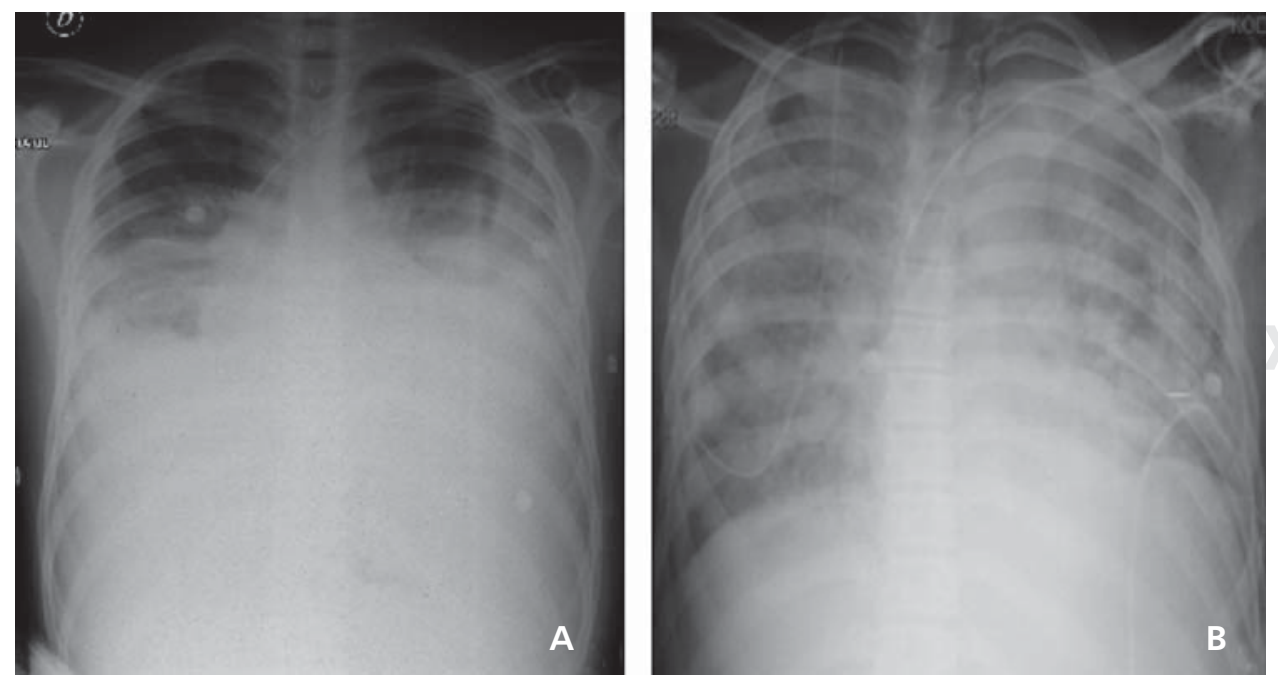

Figura 1.

En A se aprecia el derrame pleural bilateral y refractario; en $\mathbf{B}$ con remisión de la disnea clínica y del derrame radiológico posterior al drenaje percutáneo bilateral, se extrajeron 48 litros. 

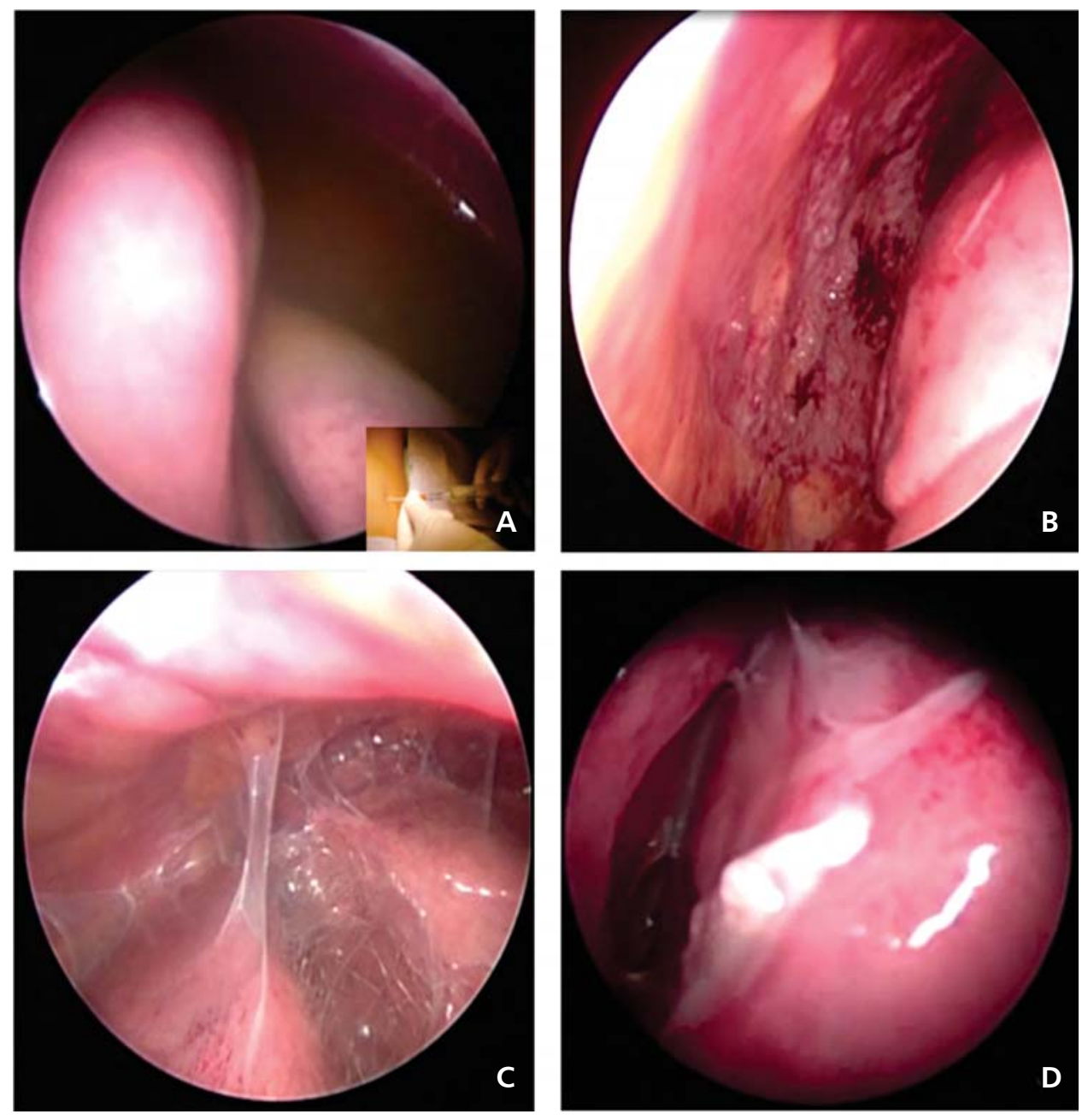

Figura 2.

La toracoscopia diagnóstica demuestra en A: el exudado inflamatorio amarillento; en B: pleuritis, nódulos pleurales y cambios inflamatorios para biopsia pleural; en C: síndrome de pulmón atrapado por adherencias interpleurales y D: adherencias interlobares.
En la afección lúpica, el derrame pleural es resultado de una reacción autoinmune indicado por la presencia de depósitos de inmunoglobulinas sobre la pleura visceral con infiltración de células plasmáticas y linfocíticas, así como la liberación de fracciones de complemento C3a y C5a, con los consecuentes trastornos de un espacio pleural inflamado con defectos de absorción y aumento de la permeabilidad capilar. ${ }^{1,2,14}$ El espacio pleural crónicamente inflamado conlleva a una pleuritis fibrótica con engrosamiento pleural y atrapamiento parenquimatoso pulmonar. Los derrames pleurales refractarios son raros y traducen la manifestación de una exacerbación lúpica severa que no responde al tratamiento convencional. El líquido pleural es usualmente un exudado amarillo o serosanguinolento con predominio de neutrófilos o monocitos, la presencia de linfocitos denota cronicidad y el diagnóstico diferencial con tuberculosis debe ser considerado. Por lo general, el $\mathrm{pH}$ es $>7.2$, la glucosa discretamente disminuida pero $>60 \mathrm{md} / \mathrm{dL}$ y la deshidrogenasa láctica $<500 \mathrm{IU} / \mathrm{l}$.
La reducción en los niveles de complemento en líquido pleural permite diferenciar a los derrames de otras enfermedades del tejido conectivo. Los ANA con títulos > 1:160 en líquido pleural y la relación de anticuerpos ANA pleural: séricos $>1$ son sugestivos, pero no diagnósticos de pleuritis lúpica. ${ }^{1-2,15}$ Ocasionalmente, las células de lupus eritematoso son encontradas en los derrames serosos de la pleuritis lúpica, aunque inespecíficas pues pueden referirse en los derrames malignos y en artritis reumatoide. La toracoscopia revela nódulos en la pleura visceral, y las biopsias pleurales sometidas a inmunofluorescencia muestran en estos nódulos depósito de inmunoglobulinas..$^{16,17}$ En ausencia de actividad lúpica, los derrames pleurales pequeños, unilaterales y con leve dolor pleurítico pueden responder a agentes antiinflamatorios no esteroideos. ${ }^{1-3} \mathrm{La}$ terapia con corticosteroides sistémicos es la piedra angular del tratamiento en la pleuritis lúpica. ${ }^{1,2,18} \mathrm{En}$ los derrames pleurales masivos y refractarios a las altas dosis de esteroides se han utilizado cursos mensuales 

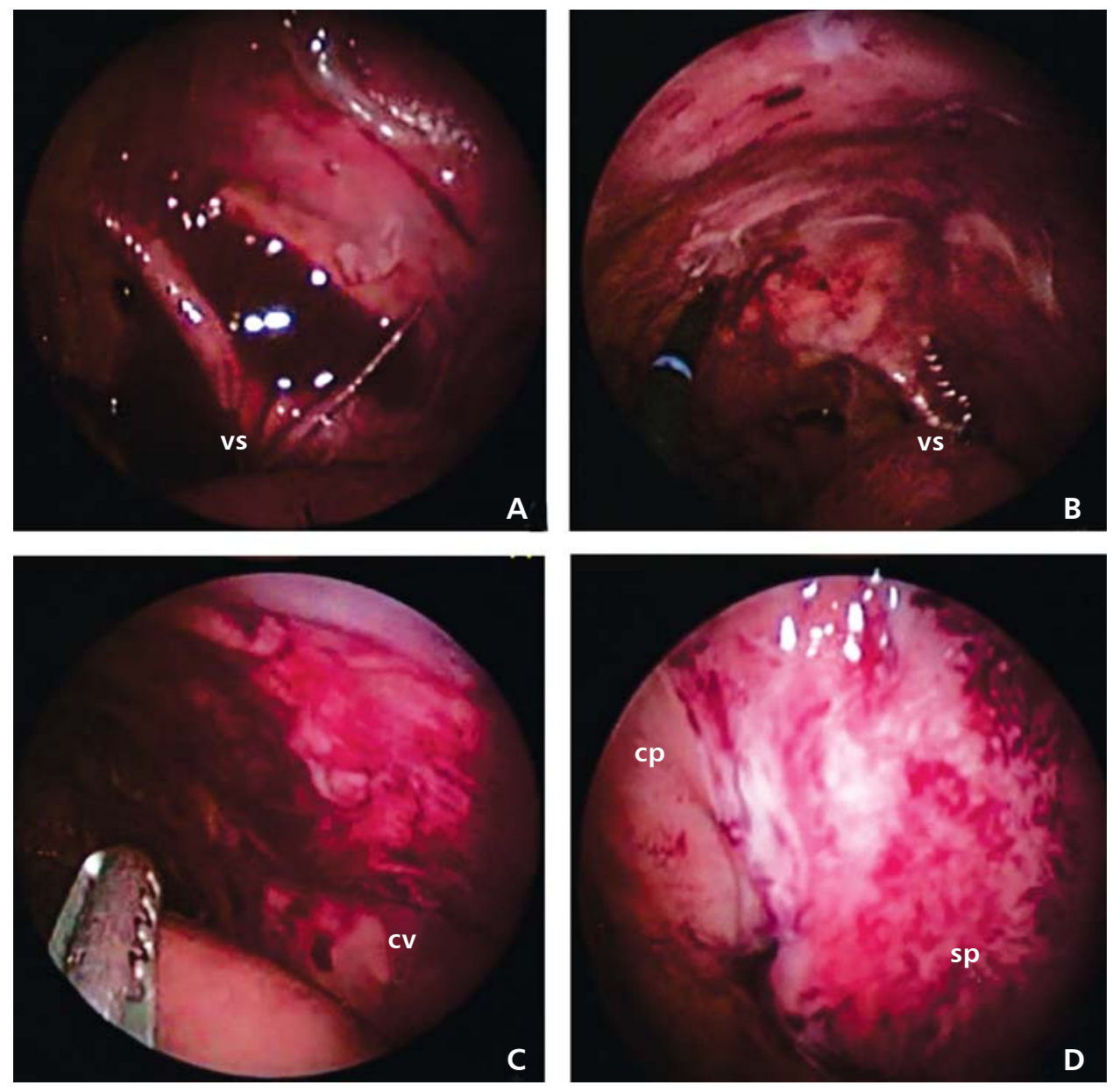

Figura 3.

Pleurectomía parcial toracoscópica que requiere en $\mathbf{A}$ : identificar los vasos subclavios (vs); B: iniciando la resección a $2 \mathrm{~cm}$ cefálicos de los vs; C: a $2 \mathrm{~cm}$ del cuerpo vertebral (cv) y D: comparativo de las superficies con pleura (cp) y sin pleura (sp). de ciclosporina y la combinación con inmunoglobulina intravenosa es referida como benéfica en la población adulta..$^{1,2,18,19} \mathrm{El}$ manejo a largo plazo puede involucrar el uso de antimaláricos como la hidroxicloroquina. En adultos se han reportado la pleurodesis con tetraciclina y con talco, así como la pleurectomía parcial o total en el tratamiento quirúrgico de estos pacientes refractarios al manejo inmunosupresor, inclusive se han considerado como opciones tempranas y definitivas de manejo., ${ }^{1,20-22}$

Los exudados bacterianos, tuberculosos, micóticos y neoplásicos deben ser excluidos; y las causas de trasudado como síndrome nefrótico, hipoalbuminemia e insuficiencia cardíaca ser corregidas oportunamente. Los esfuerzos para combatir la actividad lúpica deben ser agotados antes de considerar la refractariedad a las medidas conservadoras de tratamiento. ${ }^{23}$ Los derrames pleurales malignos del adulto explican el $75 \%$ de los derrames pleurales recurrentes y aportan la principal fuente de experiencia extrapolada a nuestra población infantil con derrame pleural lúpico. En el niño prevalecen las condiciones benignas tuberculosas, reumáticas, cardíacas, cirróticas por sarcoidosis y por lupus eritematoso sistémico. ${ }^{24}$ Cuando la toracocentesis diagnóstica y terapéuticas repetidas no ofrecen mejoría clínica e inclusive conllevan neumotórax iatrogénico, loculación y contaminación del espacio pleural, la toracoscopia videoasistida representa en esta población, la piedra angular para el diagnóstico definitivo y el tratamiento paliativo de estos derrames pleurales recurrentes.

Sin embargo, en nuestro paciente, la inserción de un catéter bajo guía metálica en el interior del espacio pleural permitió confirmar los beneficios terapéuticos del drenaje pleural con mejoría clínica de la disnea, y con mínimo riesgo de contaminación por comportarse como un sistema de drenaje cerrado estéril, al mismo tiempo que evita las toracocentesis repetidas. ${ }^{25-27}$ Más aún, ante la posibilidad de un derrame pleural tuberculoso, el drenaje pleural percutáneo favorece la evacuación segura y controlada del líquido pleural con bajo riesgo de engrosamiento pleural y la consecuente fístula 
Tabla 1. Alternativas terapéuticas para el derrame pleural refractario en lupus eritematoso sistémico.

\begin{tabular}{l}
$\begin{array}{c}\text { Indicaciones y mecanismo } \\
\text { de acción }\end{array}$ \\
\hline Leurodesis con tetraciclina a \\
$20 \mathrm{mg} / \mathrm{kg}$. Produce irritación \\
y abrasión química de las \\
superficies pleurales. Re- \\
quiere un completo drenaje \\
de la cavidad pleural y una \\
total expansión pulmonar \\
antes de la instilación intra- \\
pleural.
\end{tabular}

Pleurodesis con talco, exige las mismas indicaciones previas. Contraindicado en pulmón atrapado. Estimulación del mesotelio, activación de la coagulación pleural, formación de fibrina y proliferación de fibroblastos, fibrosis y tejido de granulación con sínfisis interpleurales.

Pleurectomía completa o parcial quirúrgicas. Indicado en pulmón atrapado y cuando otras medidas conservadoras han fallado.

\section{Ventajas y desventajas}

Técnica de administración

El procedimiento puede ser repetido. Dolor severo y uso prolongado de analgésicos narcóticos.

El procedimiento en suspensión salina puede ser repetido; el drenaje pleural debe ser pinzado por 1 hora y el paciente debe cambiar de posición cada 15 minutos para una adecuada distribución. Dolor torácico severo y posible riesgo de neumotórax; el tubo de toracostomía debe ser conectado a succión y sello de agua por 3 días. Se han reportado complicaciones: fiebre, empiema, síndrome de dificultad respiratoria (9\%), talcoma. La fibrosis podría dificultar una cirugía torácica futura.

El procedimiento por toracoscopia videoasistida o abierto ofrece el diagnóstico definitivo con toma de biopsia pleural y la obliteración y fibrosis de la cavidad pleural es asegurada; la adherensiolisis es el tratamiento de elección en el pulmón atrapado. Conlleva un riesgo anestésico y de morbilidad aceptables.
Intrapleural por tubo de toracostomía; un drenaje percutáneo transpleural no asegura el completo drenaje pleural ni la expansión pulmonar total, se asocia a complicaciones locales: loculaciones, pulmón atrapado. Lidocaína intrapleural a $1 \mathrm{~mL} / \mathrm{kg}$ al $1 \%$ previo a la instilación intrapleural reduce el dolor torácico.

Existen dos métodos: a) en instilación intrapleural como suspensión salina: $3 \mathrm{~g}$ de talco estéril libre de asbestos en $50 \mathrm{~mL}$ de solución salina y $20 \mathrm{~mL}$ de lidocaína al $2 \%$, instilados vía drenaje intrapleural; b) en polvo por toracoscopia: $2.5 \mathrm{~g}$ de talco estéril libre de asbestos, esparcido en superficie pleural bajo visión. El drenaje pleural y la expansión pulmonar por tubo de toracostomía es mandatoria.

El abordaje toracoscópico combinado con la pleurodesis con yodo povidona al $10 \%(20 \mathrm{~mL})$ con $30 \mathrm{~mL}$ de solución salina por vía intrapleural, previa impregnación local con $20 \mathrm{~mL}$ de lidocaína al $2 \%$, requiere de pinzamiento por 4 horas de la sonda pleural posinstilación y retiro de la misma en 24 horas confirmada la expansión pulmonar.
Mayor del 90\% de efectividad; es el método de pleurodesis química preferido. Aunque extrapolado de los derrames pleurales malignos del adulto, en esta revisión fue la opción conservadora más efectiva.
Efectividad cercana al $96 \%$, el método combinado con pleurodesis químicas repetidas es seguro y de manera temprana ofrece un control definitivo con baja morbilidad.

\section{WVuw mediaraphic.orch mx}

pleurocutánea descrita en los derrames tuberculosos tratados con sonda pleural de toracostomía. El drenaje pleural y la pleurodesis por instilación de agentes esclerosantes como el talco libre de asbestos han mostrado éxito del 80 al $100 \%$ en el tratamiento de los derrames pleurales malignos recurrentes, comparado con la utilidad de la tetraciclina útil sólo en el $75 \%$ de los casos. ${ }^{24,28,29}$ Estas opciones de pleurodesis química pueden resultar en adherencias pleuropulmonares en parches, loculaciones y pulmón atrapado al ser realizados como procedimiento ciego por el tubo de toracostomía. Sin embargo, la incidencia reportada de síndrome de dificultad respiratoria, fiebre y el dolor torácico asociada a la instilación de agentes esclero- 
santes ha dirigido la atención a métodos combinados de tratamiento con pleurodesis local de yodo povidona (solución al 10\%) instilados bajo visión asistida por toracoscopia, donde se adicionan la terapéutica segura y definitiva de la pleurectomía parcial o total, así como el diagnóstico definitivo de la biopsia pleural. ${ }^{30-33}$

En nuestro caso, las instilaciones repetidas con yodo povidona intrapleural por sonda de toracostomía son posibles en el seguimiento posquirúrgico y aseguran la efectividad reportada del 64 al $96 \% .^{34-36}$ La toracoscopia permite la evacuación y adherensiolisis del espacio pleural y confirma una completa expansión pulmonar, requisito indispensable para ejecutar la pleurodesis química. En pacientes con un síndrome de pulmón atrapado, la decorticación por toracoscopia con pleurectomía parietal representa el procedimiento de elección. ${ }^{24,31,37,38}$ El síndrome de pulmón atrapado con dificultades para ser resuelto por toracoscopia debe ser tratado con procedimiento abierto para decorticación y pleurectomía total, pleurodesis química adicional y considerar una derivación pleuroperitoneal. ${ }^{37-40}$

La terapia sistémica con inmunomoduladores e inmunosupresores es dirigida por un equipo experto de inmunólogos, intensivistas y neumólogos. En la tabla 1 se exponen las opciones terapéuticas conservadoras con pleurodesis química local y quirúrgicas, se detallan indicaciones, ventajas, técnicas de administración y efectividad reportadas.

Nuestro paciente representa un escenario clínico infrecuente de la pleuritis con derrame pleural bilateral masivo y refractario a manejo sistémico y conservador en el curso de un lupus eritematoso sistémico de la infancia. La revisión de la literatura sólo describe el reporte de 10 casos aislados en la población adulta, ninguno en niños, con edades entre los 20 a 48 años en donde el derrame pleural con dolor pleurítico fue la presentación temprana de lupus sistémico en tres casos, y el derrame pleural exudativo se documentó en ocho pacientes. En el diagnóstico se encontraron los niveles de complemento bajo (C3 y C4) en seis casos, y anticuerpos antiDNA positivos en siete pacientes. Todos los pacientes recibieron esteroides sistémicos (inclusive 2 intrapleurales), azatioprina, ciclosporina, ciclofosfamida, metotrexate e hidroxicloroquina, no mostraron respuesta médica. La inmunoglobulina intravenosa y la ciclosporina combinadas mostraron éxito en dos pacientes y en uno de ellos con antecedente de pleurectomía seis meses previos. La pleurodesis química con talco fue efectiva en cuatro pacientes, la tetracilina intrapleural en dos, la pleurectomía parietal en uno y la combinación de pleurectomía parcial y pleurodesis con talco en otro más concluyeron su efectividad. Ninguno de ellos mostró recurrencia a un año de vigilancia. ${ }^{30,39,40}$
Existen pues, variadas propuestas terapéuticas con dificultades para determinar la mejor opción en niños, donde la decisión se extrapola de la escasa experiencia en adultos y se propone una escala que agota tempranamente las opciones sistémicas y conservadoras hasta las opciones invasivas locales y quirúrgicas combinadas. La primera línea de tratamiento debe ser siempre el control sistémico de la enfermedad lúpica: los exudados deben ser excluidos y tratados, las causas de trasudado como síndrome nefrótico, hipoalbuminemia e insuficiencia cardíaca deben ser corregidos oportunamente; el control sistémico con terapia inmunosupresora (ciclofosfamida) y altas dosis de esteroides, la inmunoglobulina intravenosa combinada con ciclosporina podrían ser la última opción de la terapia sistémica. Las medidas esclerosantes locales con talco o yodo povidona intrapleurales por tubo de toracostomía, una vez asegurada la expansión pulmonar clínica y radiológica podrían ser la segunda línea de tratamiento conservador.

La presencia de parénquima pulmonar atrapado con derrame pleural refractario al manejo sistémico y conservador encuentra en la pleurectomía parcial videoasistida por toracoscopia, el tratamiento quirúrgico de elección y nuestra propuesta de acción temprana en estos pacientes.

\section{REFERENCIAS}

1. Bouros D, Pneumatikos I, Tzouvelekis A. Pleural involvement in systemic autoimmune disorders. Respiration 2008;75(4):361-371. doi: 10.1159/000119051.

2. Bouros D, Panagou P, Papandreou L, Kottakis I, Tegos C. Massive bilateral pleural effusion as the only first presentation of systemic lupus erythematosus. Respiration 1992;59(3):173-175.

3. Pohlgeers AP, Eid NS, Schikler KN, Shearer LT. Systemic lupus erythematosus: pulmonary presentation in childhood. South Med J 1990;83(6):712-714.

4. Haupt HM, Moore GW, Hutchins GM. The lung in systemic lupus erythematosus. Analysis of the pathologic changes in 120 patients. Am J Med 1981;71(5):791-798.

5. Quismorio FP Jr. Clinical and pathologic features of lung involvement in systemic lupus erythematosus. Semin Respir Dis 1988;9:297.

6. Nadorra RL, Landing BH. Pulmonary lesions in childhood onset systemic lupus erythematosus: analysis of 26 cases, and summary of literature. Pediatr Pathol 1987;7(1):1-18.

7. Chantarojanasiri T, Sittirath A, Preutthipan A, Tapaneya-Olarn W, Suwanjutha S. Pulmonary involvement in childhood systemic lupus erythematosus. J Med Assoc Thai 1999;82 Suppl 1:S144-S148.

8. Walz-Leblanc BA, Urowitz MB, Gladman DD, Hanly PJ. The "shrinking lungs syndrome" in systemic lupus erythematosus improvement with corticosteroid therapy. J Rheumatol 1992;19(12):1970-1972. 
9. Rubin LA, Urowitz MB. Shrinking lung syndrome in SLE a clinical pathologic study. J Rheumatol 1983;10(6):973-976.

10. Winslow WA, Ploss LN, Loitman B. Pleuritis in systemic lupus erythematosus: its importance as an early manifestation in diagnosis. Ann Intern Med 1958;49(1):70-88.

11. Alarcón-Segovia D, Alarcón DG. Pleuro-pulmonary manifestations of systemic lupus erythematosus. Dis Chest 1961;39:7-17.

12. Caeiro F, Michielson FM, Bernstein R, Hughes GR, Ansell BM. Systemic lupus erythematosus in childhood. Ann Rheum Dis 1981;40(4):325-331.

13. de Jongste JC, Neijens HJ, Duiverman EJ, Bogaard JM, Kerrebijn KF. Respiratory tract disease in systemic lupus erythematosus. Arch Dis Child 1986;61(5):478-483.

14. Chandrasekhar AJ, Robinson J, Barr L. Antibody deposition in the pleura: a finding in drug-induced lupus. J Allergy Clin Immunol 1978;61(6):399-402.

15. Khare V, Baethge B, Lang S, Wolf RE, Campbell GD Jr. Antinuclear antibodies in pleural fluid. Chest 1994;106(3):866-871.

16. Pertschuk LP, Moccia LF, Rosen Y, et al. Acute pulmonary complications in systemic lupus erythematosus. Immunofluorescence and light microscopic study. Am J Clin Pathol 1977;68(5):553-557.

17. Keane MP, Lynch JP 3rd. Pleuropulmonary manifestations of systemic lupus erythematosus. Thorax 2000;55(2):159-166.

18. Brasington RD, Furst DE. Pulmonary disease in systemic lupus erythematosus. Clin Exp Rheumatol 1985;3(3):269-276.

19. Sherer Y, Langevitz P, Levy Y, Fabrizzi F, Shoenfeld Y. Treatment of chronic bilateral pleural effusions with intravenous immunoglobulin and cyclosporin. Lupus 1999;8(4):324-327.

20. McKnight KM, Adair NE, Agudelo CA. Successful use of tetracycline pleurodesis to treat massive pleural effusion secondary to systemic lupus erythematosus. Arthritis Rheum 1991;34(11):1483-1484.

21. Kaine JL. Refractory massive pleural effusion in systemic lupus erythematosus treated with talc poudrage. Ann Rheum Dis 1985;44(1):61-64.

22. Gilleece MH, Evans CC, Bucknall RC. Steroid resistant pleural effusion in systemic lupus erythematosus treated with tetracycline pleurodesis. Ann Rheum Dis 1988;47(12):1031-1032.

23. D'Cruz D, Khamashta M, Hughes G. Pulmonary manifestations of systemic lupus erythematosus. In: Wallace DJ, Hahn BH, editors. Dubois lupus erythematosus. 6th ed. Philadelphia, Lippincott: Williams and Wilkins; 2002. p. 663-684.

24. Cardillo G, Facciolo F, Carbone L, et al. Long-term follow up of video-assisted talc pleurodesis in malignant recurrent pleural effusions. Eur J Cardiothorac Surg 2002;21(2):302-305.

25. Saffran L, Ost DE, Fein AM, Schiff MJ. Outpatient pleurodesis of malignant pleural effusions using a smallbore pigtail catheter. Chest 2000;118(2):417-421.

26. Anderson CB, Philpott GW, Ferguson TB. The treatment of malignant pleural effusions. Cancer 1974;33(4):916-922.
27. Parulekar W, Di Primio G, Matzinger F, Dennie C, Bociek G. Use of small- bore vs. large bore chest tubes for treatment of malignant pleural effusions. Chest 2001;120(1):19-25.

28. Grossi F, Pennucci MC, Tixi L, Cafferata MA, Ardizzoni A. Management of malignant pleural effusions. Drug 1998;55(1):47-58.

29. Petrou M, Kaplan D, Goldstraw P. Management of recurrent malignant pleural effusions. The complementary role talc pleurodesis and pleuroperitoneal shunting. Cancer 1995;75(3):801-805.

30. Breuer GS, Deeb M, Fisher D, Nesher G. Therapeutic options for refractory massive pleural effusion in systemic lupus erythematosus: a case study and review of the literature. Semin Arthritis Rheum 2005;34(5):744-749.

31. de Campos JR, Vargas FS, de Campos WE, et al. Thoracoscopy talc poudrage: a 15 year experience. Chest 2001;119(3):801-806.

32. Bondoc AY, Bach PB, Sklarin NT, Vander Els NJ. Arterial desaturation syndrome following pleurodesis with talc slurry: incidence, clinical features, and outcome. Cancer Invest 2003;21(6):848-454.

33. Rehse DH, Aye RW, Florence MG. Respiratory failure following talc pleurodesis. Am J Surg 1999;177(5):437-440.

34. Mohsen TA, Zeid AA, Meshref $M$, et al. Local iodine pleurodesis versus thoracoscopic talc insufflation in recurrent malignant pleural effusion: a prospective randomized control trial. Eur J Cardthorac Surg 2011;40(2):282-286. doi: 10.1016/j.ejcts.2010.09.005.

35. Olivares-Torres CA, Laniado-Laborín R, Chávez-García C, León-Gastelum C, Reyes-Escamilla A, Light RW. Iodopovidone pleurodesis for recurrent pleural effusions. Chest 2002;122(2):581-583.

36. Kelly-García J, Roman-Berumen JF, Ibarra-Pérez C. Iodopovidone and bleomycin pleurodesis for effusions due to malignant epithelial neoplasms. Arch Med Res 1997;28(4):583-585.

37. Schulze M, Boehle AS, Kurdow R, Dohrmann P, HenneBruns D. Effective treatment of malignant pleural effusions by minimal invasive thoracic surgery: thoracoscopic talc pleurodesis and pleuroperitoneal shunts in 101 patients. Ann Thorac Surg 2001;71(6):1809-1812.

38. Elborn JS, Conn P, Roberts SD. Refractory massive pleural effusions in systemic lupus erythematosus treated by pleurectomy. Ann Rheum Dis 1987;46(1):77-80.

39. Martini N, Bains MS, Beattie EJ Jr. Indications for pleurectomy in malignant effusion. Cancer 1975;35(3):734-738.

40. Bell R, Lawrence DS. Chronic pleurisy in systemic lupus erythematosus treated with pleurectomy. Br J Dis Chest 1979;73(3):314-316.

\section{$\triangle$ Correspondencia: \\ Dr. Rogelio Sancho Hernández, Neumología y \\ Cirugía de Tórax Pediátrica. Instituto Nacional de \\ Pediatría, Ciudad de México, D.F. Insurgentes Sur \\ 3700-C, Colonia Insurgentes Cuicuilco. \\ Correo electrónico: saherog@yahoo.com.mx}

Los autores declaran no tener conflicto de intereses. 